\title{
Habitat Preferences and Site Fidelity of the Ornate Wobbegong Shark (Orectolobus ornatus) on Rocky Reefs of New South Wales ${ }^{1}$
}

\author{
Robert Carraro ${ }^{2}$ and William Gladstone ${ }^{2,3}$
}

\begin{abstract}
Habitat and microhabitat preferences and site fidelity of Orectolobus ornatus were assessed between September 2002 and August 2003 to assess potential suitability of marine reserves for its conservation. Of six rocky reef habitats available in the study area (sponge gardens, artificial structures, barren boulders, sand, sea grass, macroalgae), O. ornatus exhibited a significant preference for sponge gardens, artificial structures, and barren boulders habitats. Habitat preferences of males and females, and individuals $<1 \mathrm{~m}$ and $>1 \mathrm{~m}$, did not differ. Orectolobus ornatus selected daytime resting positions with a high topographic complexity and crevice volume and did not select on the basis of prey availability. Habitat and microhabitat preferences may be related to the need for predator avoidance. Regular monitoring of 40 individually identified O. ornatus revealed that none was a permanent resident of the study area. Seven individuals exhibited short-term temporary fidelity to the study area; they were resighted frequently for part of an intensive 100-day survey. Remaining individuals were temporary visitors; they were resighted at most once after initial identification or returning after extended absences. Monthly population surveys confirmed the turnover of O. ornatus in the study area. The lack of long-term site fidelity suggests that small marine reserves will be ineffective as a conservation strategy for O. ornatus.
\end{abstract}

A PRIMARY requirement for conserving marine species is an understanding of the processes underlying patterns in distribution and abundance (Bell et al. 1991). One such factor that has received considerable attention is habitat variation. The patchy distribution of habitats influences distribution and abundance at many spatial scales (Syms 1995). Habitat structure or quality of habitats may limit populations through the availability of critical resources and may modify ecological

${ }^{1}$ This research was funded by grants from the University of Newcastle and is a contribution from the Centre for Sustainable Use of Coasts and Catchments. Manuscript accepted 2 June 2005.

${ }^{2}$ Centre for Sustainable Use of Coasts and Catchments, School of Applied Sciences, University of Newcastle (Ourimbah Campus), P.O. Box 127, Ourimbah, New South Wales 2258, Australia.

${ }^{3}$ Corresponding author (e-mail: william.gladstone@ newcastle.edu.au).

Pacific Science (2006), vol. 60, no. 2:207-223

(C) 2006 by University of Hawai'i Press

All rights reserved processes such as competition, predation, and recruitment (Jones and Syms 1998). The importance of habitat has received increasing attention from conservation biologists because anthropogenic degradation of habitat is a primary cause of global declines in biodiversity and as spatial approaches to conservation and management (such as marine protected areas) are increasingly utilized (Ray and McCormick-Ray 2004). Understanding the importance of habitat for species requires the separation of habitat usage and preference, where habitat usage includes the habitats in which individuals occur and habitat preference is a species' use of a habitat in relation to its relative availability (Manly et al. 1993).

Although elasmobranch nursery habitats have been well studied, there are few studies of usage and preference for other life stages and habitats, despite the critical importance of habitat in determining distribution and abundance and the application of this information for conservation planning (Simpfendorfer and Heupel 2004). The available 
quantitative studies of habitat preference demonstrate fine-scale discrimination among available habitats. Juvenile lemon sharks (Negaprion brevirostris) prefer habitats less than $50 \mathrm{~cm}$ depth, with water temperature greater than $29^{\circ} \mathrm{C}$, and consisting of a mixture of rock and sand (Morrisey and Gruber 1993a). Tiger sharks (Galeocerdo cuvier) in Shark Bay, Western Australia, prefer shallow sea-grass beds, where their prey is more abundant (Heithaus et al. 2002). With the exception of general habitat descriptions little data have been obtained for the habitat usage of wobbegong sharks. There is, therefore, considerable scope for studies of habitat preference in this and other shark species of conservation significance whose habitat is affected by human activities.

The related concept of site fidelity expresses the temporal attachment of an individual to a space in its habitat. The degree of site fidelity varies in relation to the availability and defensibility of critical resources and ranges between strict territoriality, shared home ranges, and nomadism, although territoriality has not been demonstrated in sharks (Heithaus 2004). Site fidelity is known to occur at some stage in the life cycle of a number of sharks (McKibben and Nelson 1986, Holland et al. 1993, Morrissey and Gruber 1993b, Goldman and Anderson 1999, Rechisky and Wetherbee 2003). The existence of site fidelity will determine the likely success of spatially based management strategies such as marine protected areas (Kramer and Chapman 1999). Further understanding of the existence of site fidelity in sharks is important in assessing the potential usefulness of marine protected areas for conservation and management.

Two species of wobbegong sharks (family Orectolobidae) occur in southeastern Australia: Orectolobus ornatus (De Vis, 1883) and $O$. maculatus (Bonnaterre, 1788). Both species are demersal, inhabit temperate rocky reefs, and are likely to have an important functional significance because of their role as top predators (Last and Stevens 1994). Wobbegongs are caught by commercial fishers in New South Wales as a target group and as bycatch. Declines in annual catches of $>60 \%$ between 1990 and 2000 raised concerns about the status of wobbegong populations (NSW Fisheries 2002a). Other sources of anthropogenic mortality include recreational fishing and protective beach meshing programs (Pogonoski et al. 2002). Due to recent declines in populations, $O$. ornatus has been classified as vulnerable in New South Wales and nearthreatened throughout its range (Cavanagh et al. 2003). Marine reserves have been advocated as a strategy to conserve wobbegong sharks (Otway and Parker 2000, NSW Fisheries 2002b). However, the ecological understanding about wobbegongs necessary for evaluating the potential usefulness of marine reserves is lacking (Pogonoski et al. 2002). This lack of information is a critical gap given the conservation and management concerns for this species. The aims of this study were to determine (1) habitat preferences and (2) site fidelity of O. ornatus and to use this information to assess the potential usefulness of marine reserves as a conservation and management strategy.

\section{MATERIALS AND METHODS}

\section{Study Species}

Orectolobus ornatus is a nocturnal benthic predator that occurs in all Australian states and Papua New Guinea to a depth of at least $100 \mathrm{~m}$. During daylight hours it rests in protected parts of reefs. Orectolobus ornatus is ovoviviparous and pups are born at $\sim 20 \mathrm{~cm}$ length, with adults growing to a maximum length of $\sim 300 \mathrm{~cm}$. Sexual maturity is believed to occur at $175 \mathrm{~cm}$ length (Last and Stevens 1994).

\section{Study Area}

This study occurred between September 2002 and August 2003 in the Fly PointHalifax Park Aquatic Reserve (hereafter "the reserve") in Port Stephens, New South Wales, Australia, at $32^{\circ} 42^{\prime} 50^{\prime \prime} \mathrm{S}, 152^{\circ} 9^{\prime}$ $20^{\prime \prime} \mathrm{E}$ (Figure 1). Habitats within the reserve were typical of those present in adjacent nearshore areas (Underwood et al. 1991) and included fringe (dominated by foliose macro- 

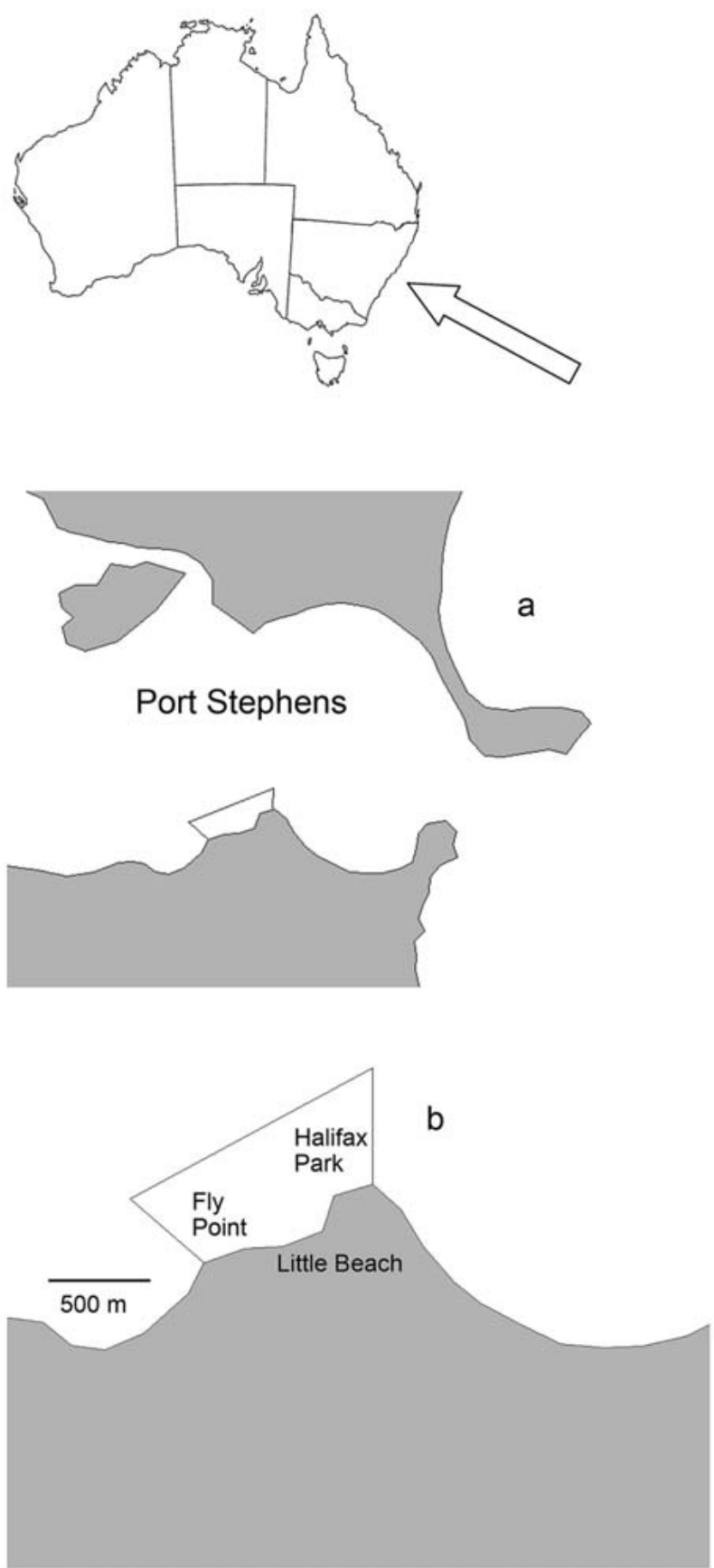

Figure 1. Location of study areas $(a)$ within Port Stephens and $(b)$ within the Fly Point-Halifax Park Aquatic Reserve. The boundary of the reserve is shown within the waters of Port Stephens and the land is shaded gray. 
algae in depths of 1-8 m), barren boulders (with high coverage of crustose coralline algae and high abundance of the sea urchin Centrostephanus rodgersii in depths of 2-12 $\mathrm{m}$ ), sponge gardens (high coverage of encrusting and foliose sponges and limited coverage of algae in depths of 10-20 m), sand, sea grass (Posidonia australis, Halophila ovalis, and Zostera capricorni), and artificial structures (small sunken boats, refuse, and artificial reefs constructed of metal frames in depths of 6 $12 \mathrm{~m})$. Observations reported here were undertaken at three sites in the reserve: Fly Point, Little Beach, and Halifax Park. Fixed transects of $500-\mathrm{m}$ length by $5-\mathrm{m}$ width that covered all habitats and the depth range of each site were established at the beginning of the study. The boundaries of the transects were noted in relation to prominent substratum features.

\section{Habitat Availability and Preferences}

The relative availability of each habitat in the reserve was determined by divers using the point transect method (Choat and Bellwood 1985). Three $150-\mathrm{m}$ line transects were laid across the reef and perpendicular to the shore in each of the three sites. A length of $150 \mathrm{~m}$ was used because this was the distance from the shore at which the rocky reef ended on sand (at depths of 18-25 m). At 20-m intervals along the transect the habitat below the tape measure was recorded, giving a total of 63 point counts of habitat type in the reserve.

Underwater visual surveys of the fixed transects were used to locate $O$. ornatus and to record the habitat in which each individual occurred. All crevices and overhangs on the transects were inspected for O. ornatus. For each observed $O$. ornatus the habitat in which it occurred, its sex, and its total length were noted on waterproof paper. Total length was measured with a marked fiberglass pole placed parallel to the shark's body on the substratum. Replicate surveys of each site to determine habitat preferences of $O$. ornatus were done in October 2002 ( $n=4$ surveys), January ( $n=4$ surveys), April ( $n=2$ surveys), and June 2003 ( $n=3$ surveys) and the results combined for analysis.
Habitat preferences were determined from resource selection ratios (Manly et al. 1993) using the formula $\hat{w}_{i}=o_{i} / \pi_{I}$, where $o_{i}$ is the proportion of habitats used that are in category $i, \pi_{I}$ is the proportional availability of habitat $i$, and $\hat{w}_{i}$ is the preference score for habitat category $i$. The standard error (SE) of $\hat{w}_{i}$ was calculated by $\mathrm{SE}\left(\hat{w}_{i}\right)=$ $\hat{w}_{i} \sqrt{\left\{1 / u_{i}-1 / u_{+}+1 / m_{i}-1 / m_{+}\right\}}$, where $u_{i}$ is the number of sharks in habitat $i, u_{+}$is the total number of observations of sharks, $m_{i}$ is the frequency of occurrence of habitat $i$, and $m_{+}$is the total occurrence of all habitats. $\hat{w}_{i} 95 \%$ confidence intervals were calculated from $\hat{w}_{i} \pm Z_{\alpha /(I)} \mathrm{SE}\left(\hat{w}_{i}\right)$, where $Z_{\alpha /(I)}$ is the $100 \alpha /(I)$ percentage point of the standard normal distribution and $I$ is the number of habitat groups. A Bonferroni correction was applied by dividing the $\alpha$ significance level (0.05) by the number of habitat groups to allow for multiple comparisons between all habitat categories. Confidence intervals were used to determine the significance of preference scores. When the upper confidence interval was $<1$, the habitat was significantly avoided. When the confidence interval fell between $<1$ and $>1$, the habitat was used in proportion to its availability (i.e., no preference or avoidance was exhibited). When the lower confidence interval was $>1$, the habitat was significantly preferred.

Production of a detailed underwater map of the Halifax Park site provided depth data that was used, in the same manner as the calculation of habitat preferences, to determine depth preferences of $O$. ornatus observed at this site.

\section{Microbabitat Attributes of Resting Positions}

The microhabitat attributes of each site were assessed from 21 quadrats ( 2 by $2 \mathrm{~m}$ ) randomly positioned over the depth range and in all habitats. A 2 by $2 \mathrm{~m}$ quadrat was used to simulate the area occupied by a resting $O$. ornatus. Microhabitat attributes quantified in each quadrat included depth (in $\mathrm{m}$ ) at the center of the quadrat, slope of the substratum within the quadrat (scored as none $=0,1-$ $15^{\circ}=1,15-30^{\circ}=2,30-45^{\circ}=3,45-60^{\circ}=$ $4,60-75^{\circ}=5,75-90^{\circ}=6$ ), and average vol- 
ume of all crevices/holes in the quadrat (based on measurements of longest width, breadth, and depth of each hole or crevice in the quadrat). Substrate rugosity within the quadrat was calculated from the length of a tape measure (in $\mathrm{cm}$ ) required to follow the substrate contours from one side of the quadrat to the other side and expressed as a ratio to the straight-line distance $(200 \mathrm{~cm})(\mathrm{Mc}-$ Cormick 1994). The average value from three replicate ratios was used. Orectolobus ornatus is a piscivore (Last and Stevens 1994), and the possibility that $O$. ornatus was selecting resting positions in response to prey availability was tested by recording fish abundance before placing the quadrat. As the observer approached the position where the quadrat was to be placed, the abundance of all fish occurring on the substratum and in the water column for a distance of $3 \mathrm{~m}$ above the substratum was estimated and scored in the following abundance classes: no fish $=0,1-10$ fish $=1,11-25$ fish $=2,26-50$ fish $=3$, $>50$ fish $=4$.

The microhabitat attributes of the diurnal resting positions of $O$. ornatus were recorded for individuals observed in the October 2002 surveys of habitat preferences $(n=49)$. A small weighted, subsurface marker buoy was placed on the substratum adjacent to individuals observed during the habitat-preference surveys to identify the resting position and it was revisited within $24 \mathrm{hr}$ to record the microhabitat attributes. Sharks still present at the resting position were gently displaced to allow placement of the 2 by $2 \mathrm{~m}$ quadrat.

Principal Components Analysis (PCA) was used to determine the relative importance of microhabitat attributes in resting site selection. Substrate rugosity and crevice volume were $\log$ transformed and depth was squareroot transformed before analysis and PCA performed using Euclidean distance as the distance measure following normalization. Microhabitat attributes of random quadrats and shark resting positions were displayed on a PCA ordination and differences between the relative positions of points interpreted from principal components 1 and 2. Component loadings with an absolute value $>0.50$ were regarded as important (Tabachnick and
Fidell 1989). One-way analysis of similarities (ANOSIM) was used to test whether the multivariate set of microhabitat attributes of resting positions differed significantly from the multivariate set of microhabitat attributes of the randomly selected positions. PCA and ANOSIM were undertaken with PRIMER5 software (Primer-E Ltd., Plymouth [Clarke and Warwick 2001]).

\section{Site Fidelity}

The degree of site fidelity by O. ornatus to the area of the reserve was determined by monitoring the movements and positions of 40 individually identifiable sharks for 100 days (following the date of their identification) between September 2002 and April 2003. Orectolobus ornatus were individually identified by tagging, photography, and drawing. A dart tag with a unique identification number was implanted with a handspear into the dorsal musculature anterior to the first dorsal fin. Dart tags implanted in this position on other species produced only localized tissue disruption (Heupel and Bennett 1997). The same result was observed for $O$. ornatus and suggested that the health and behavior of the tagged individuals were unaffected by the procedure. Only sharks $>1 \mathrm{~m}$ total length (TL) $(n=7)$ were tagged to reduce possible adverse effects from tagging smaller sharks (Kohler and Turner 2001). For sharks $<1 \mathrm{~m}$ TL photographs $(n=16)$ and drawings $(n=17)$ were used to record the individually unique pattern of dots and other markings on the head and distinctive fin injuries on the dorsal or caudal fins. The use of both patterns in external markings and fin injuries to identify individuals, and the duration of the observation period (100 days), meant that individuals identified by these means were unlikely to be mistakenly identified. In addition, all identifications of individual sharks were done by the same observer throughout the study. Resightings of these individually identified sharks were noted during the habitat-preference surveys, monthly population surveys (see later in this section), and specific surveys undertaken to search for these individuals. Resighting frequency was 
thus determined from 12 surveys of the reserve over the 100-day period, with an average interval of 8 days between successive surveys.

The frequency distribution of resightings of individually identified O. ornatus was used to indicate the degree of site fidelity. The total numbers of resightings of each individual were recorded and the difference between the resighting frequency distribution and a Poisson distribution was tested by $G$-test (Sokal and Rohlf 1995). A Poisson distribution was used because no significant difference between it and the resighting frequency distribution would indicate that resightings were randomly distributed and the majority of individuals were unlikely to be present in the reserve for the duration of the observation period (Pielou 1977, Samoilys 1997).

Fidelity by $O$. ornatus to specific resting positions was tested at the Halifax Park site by plotting the location of all $O$. ornatus observed during the habitat preference and monthly population surveys (see following paragraph) on a detailed underwater map of the site.

Further information on the possible existence of long-term site fidelity was gathered from data on temporal patterns in abundance, sex ratio, and length of $O$. ornatus. The absence of a stable pattern in these three variables over the study period would indicate that the population of $O$. ornatus in the study area did not exhibit high site fidelity. Surveys of the fixed transects were undertaken monthly by divers between September 2002 and August 2003 in each site. Data from each site were combined for analyses. Data were collected from repeated monthly surveys of a fixed transect, and so the replicate scores were not independent. Repeated measures analysis of variance (ANOVA) was used, with time as the repeated measures factor, to test the null hypothesis that abundance of $O$. ornatus did not vary through time. Huynh-Feldt's epsilon was used to test the assumption of sphericity (Quinn and Keough 2002). A one-way ANOVA was used to test the null hypothesis that mean length of sharks did not vary between months, and Levene's test was used to test the assumption of homogeneity of variances. A randomization procedure (Manly 1997, Legendre and Legendre 1998) was used to obtain a significance level for the observed $F$ value because it is likely that the monthly samples were not independent due to a degree of site fidelity by the sharks (see Results). The randomization procedure works by calculating an observed $F$ value from the gathered data and then randomly assigning observations to each month (while maintaining the same monthly sample size). To obtain a frequency distribution of $F$ values 5,000 randomizations of the data were used, and the significance level of the observed $F$ value was the percentage of randomized $F$ values equal to or larger than it (Manly 1997). A chi-square contingency test (Sokal and Rohlf 1995) was used to test the null hypothesis that sex ratio did not vary through time, with randomization also used to determine the significance of the obtained Pearson chi-square statistic.

\section{RESULTS}

\section{Habitat Preferences}

The relative availability of habitats in the reserve was sand $34.5 \%$, sponge gardens $20.3 \%$, barren boulders $15.5 \%$, fringe $19.6 \%$, sea grass $7.7 \%$, and artificial structures $2.4 \%$. A total of 283 observations of $O$. ornatus was recorded during the habitat-preference surveys, and the habitats occupied included sand (3.0\% observations), sponge gardens $(37.0 \%)$, barren boulders (24.2\%), fringe $(18.6 \%)$, and artificial structures (17.2\%). No O. ornatus were observed in sea-grass beds. Significance tests of preference scores indicated that $O$. ornatus preferred sponge gardens, barren boulders, and artificial structures habitats; avoided sand habitat; and exhibited no preference for fringe habitat (Figure $2 a$ ). The same pattern of habitat preferences was shown by males and females and by sharks $<1 \mathrm{~m}$ and $>1 \mathrm{~m}$ TL (Figures $2 b$ and $3 a$ ). Orectolobus ornatus at the Halifax Park site preferred depths of 4-12 and 16$20 \mathrm{~m}$, showed no selection for depths $<4 \mathrm{~m}$, and avoided depths of $12-16$ and $>20 \mathrm{~m}$ (Figure 3b). 

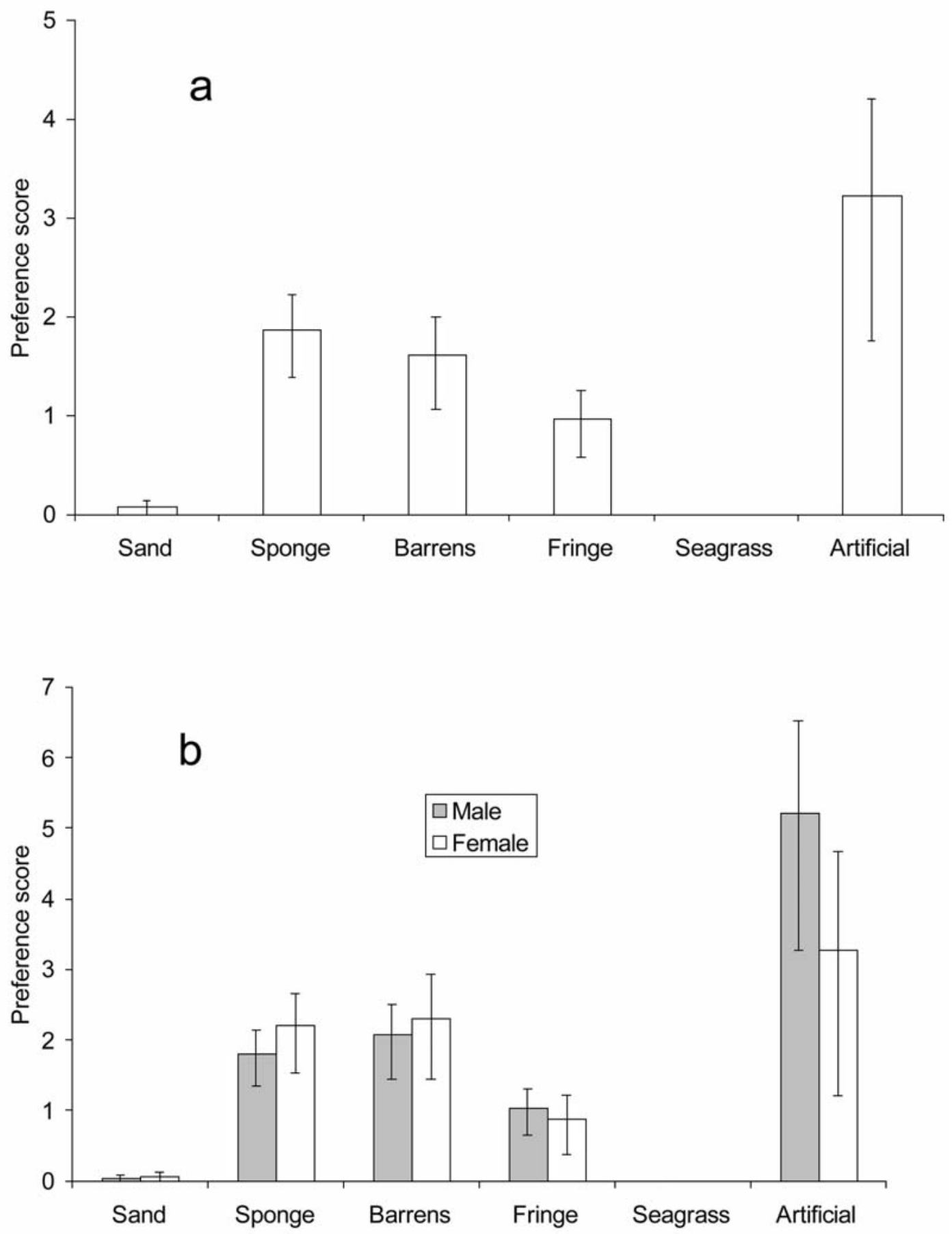

FIGURE 2. Habitat preferences of (a) all Orectolobus ornatus, (b) males and females. Values shown are preference scores and their $95 \%$ confidence intervals. Habitat preference scores with lower confidence limit $>1$ indicate a significant preference; confidence intervals that range from $<1$ to $>1$ indicate no significant preference; an upper confidence limit $<1$ indicates significant avoidance. 

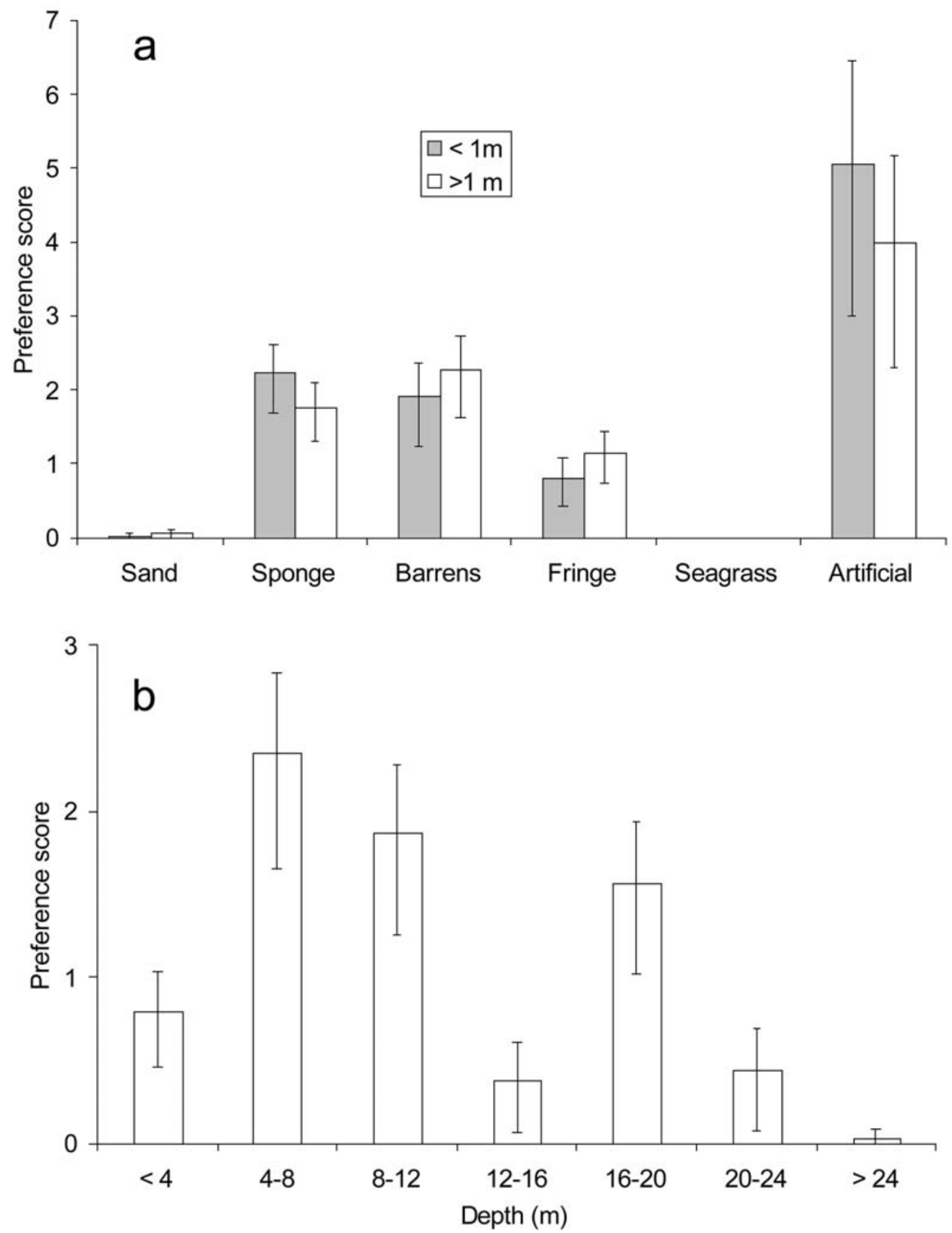

FIgUre 3. Habitat preferences of Orectolobus ornatus: (a) two classes of total length, and $(b)$ depth preferences. Values shown are preference scores and their $95 \%$ confidence intervals. Habitat preference scores with lower confidence limit $>1$ indicate a significant preference; confidence intervals that range from $<1$ to $>1$ indicate no significant preference; an upper confidence limit $<1$ indicates significant avoidance. 
TABLE 1

Summary of Principal Component Axis Loadings (Only the First Three PCs Are Shown)

\begin{tabular}{lrrr}
\hline \hline Variable & PC1 & PC2 & PC3 \\
\hline Slope & 0.23 & $\mathbf{0 . 6 3}$ & $\mathbf{0 . 6 7}$ \\
Fish abundance & 0.41 & -0.26 & -0.07 \\
Depth & -0.01 & $\mathbf{0 . 7 3}$ & $-\mathbf{0 . 6 4}$ \\
Rugosity & $\mathbf{0 . 6 3}$ & 0.03 & 0.13 \\
Crevice volume & $\mathbf{0 . 6 1}$ & -0.09 & -0.34 \\
Cumulative \% total variation & 36.7 & 57.7 & 77.6
\end{tabular}

Note: Components with an absolute value of $>0.5$ (in bold) are important (Tabachnick and Fidell 1989).

\section{Microbabitat Attributes of Resting Positions}

Orectolobus ornatus used resting positions that differed significantly in their multivariate set of microhabitat attributes from randomly selected positions on the reef that were not used as resting positions $(R=0.18, P=$ 0.001). In the principal components analysis used to determine the specific attributes that were selecting in their resting positions the first three PCs explained $77.6 \%$ of the variation in the raw data (Table 1, Figure 4). The PC1 axis represented an increasing gradient for two features of substrate complexity (rugosity and crevice volume), and the PC2

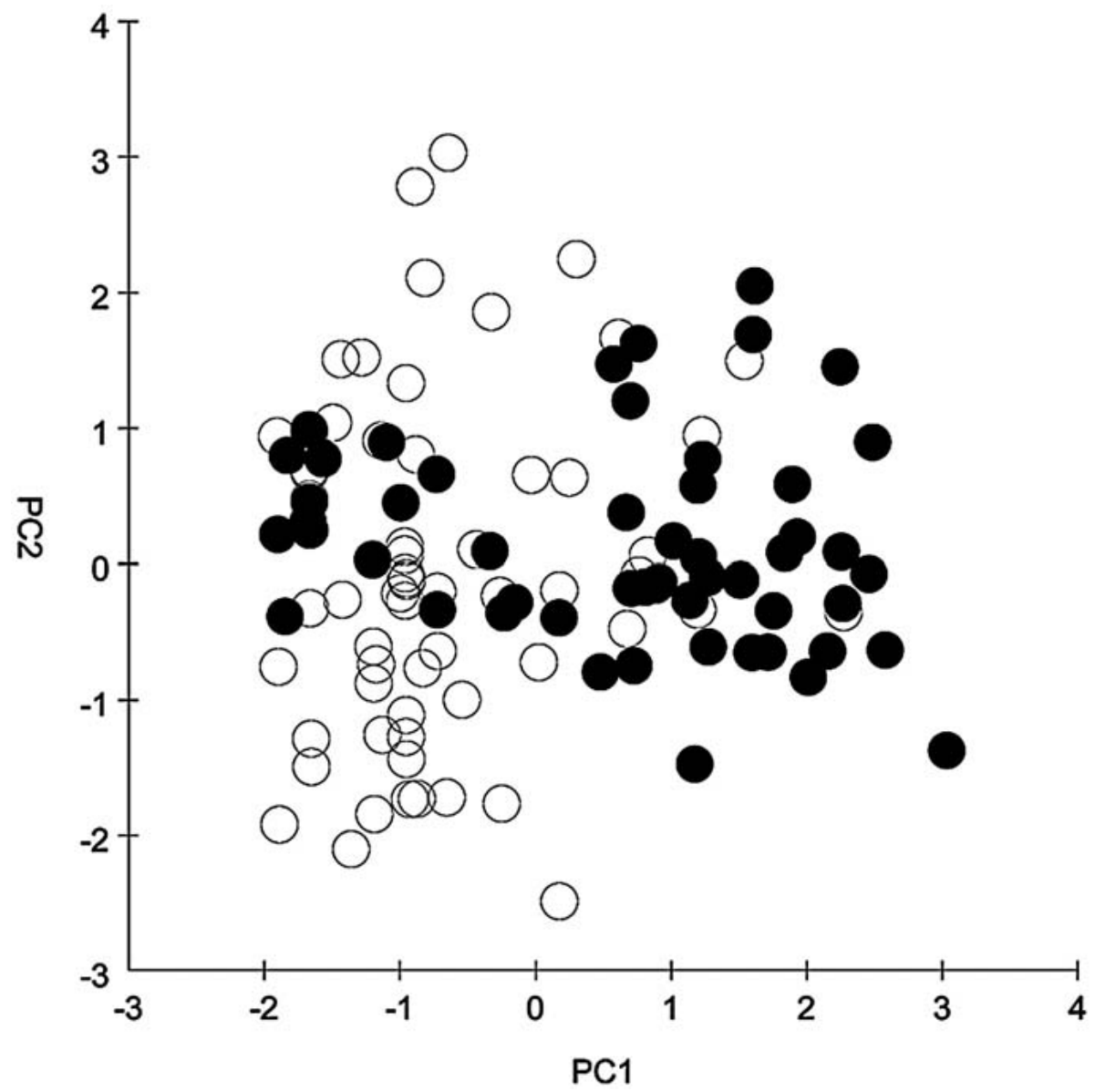

FIGURE 4. Principal components plots comparing microhabitat attributes of a random selection of positions (O) and microhabitat attributes of resting positions of Orectolobus ornatus $(\bullet)$. 


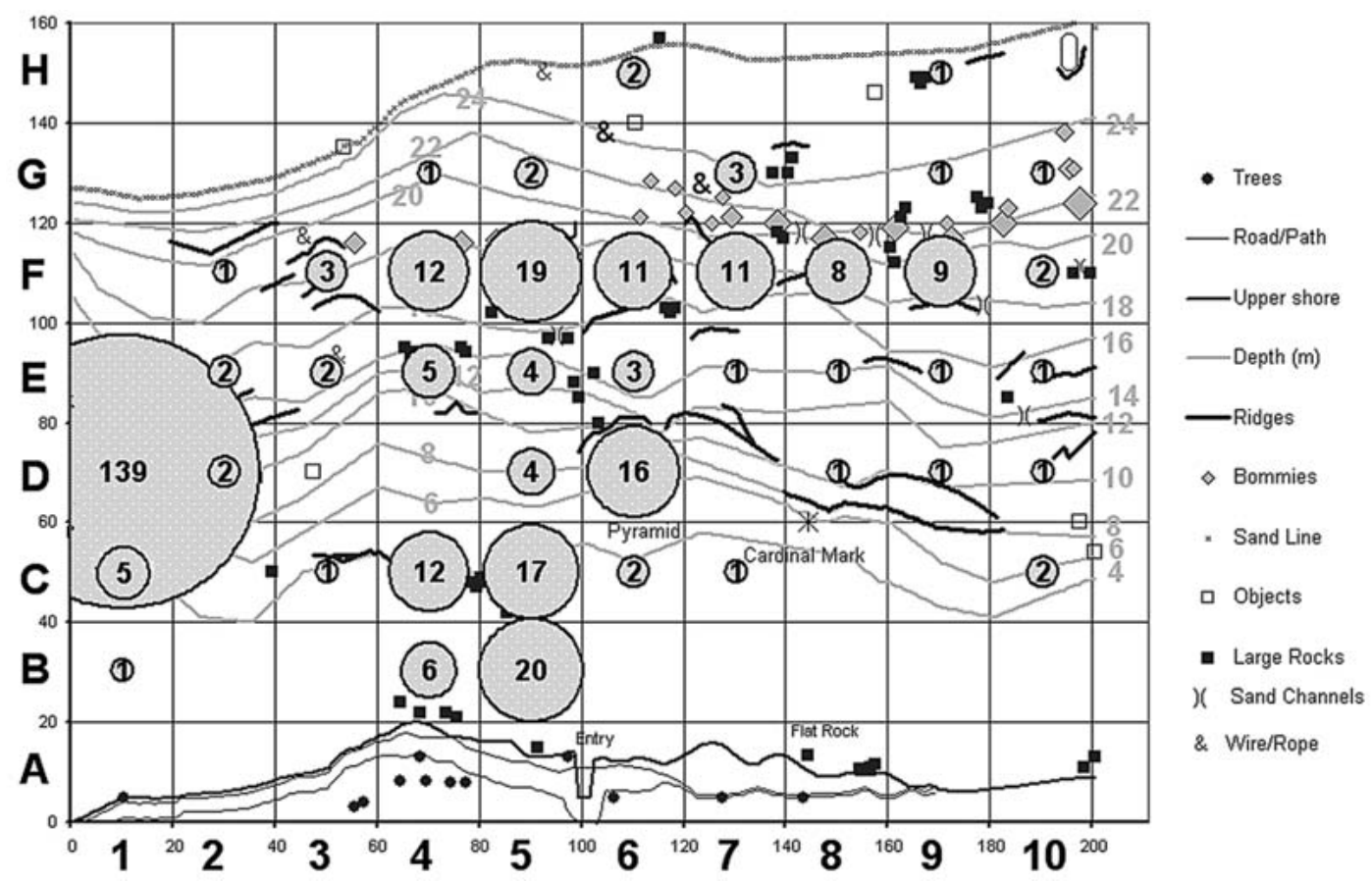

Figure 5. Relative sighting frequency of Orectolobus ornatus at the Halifax Park site, as indicated by the size of the shaded circles. Values in bold refer to the number of sightings in a 20 by $20 \mathrm{~m}$ grid cell between September 2002 and August 2003, and grid cells without numbers indicate no sightings.

axis represented an increasing gradient for depth. The topographic complexity and crevice volume of resting positions were generally greater than randomly selected positions, and the depth range of resting positions (3-21 m) was smaller than the depth range of the randomly selected positions $(0.5-25 \mathrm{~m})$. The PC3 axis (not shown in Figure 4) represented increasing reef slope and indicated that most $O$. ornatus resting positions occurred where reef slope was low.

Orectolobus ornatus used some parts of Halifax Park for resting positions more frequently than others (Figure 5), in particular grid positions D1, D6, F4-F7, B5, and C5. D1, where the highest frequency of sightings occurred, is an area of a steep slope within the barren boulders habitat comprising boulders 1-2 $\mathrm{m}$ in height and with numerous crevices and recesses. The frequency of occupation of resting positions was unrelated to the number of times each position was surveyed $(r=0.25, P=0.17$, significance de- termined by randomization because of nonindependence of observations), indicating that the observed patterns reflect selection by $O$. ornatus rather than survey effort. Over time, different individuals successively used the same crevice. A crevice at D1 was used successively by four different sharks over 150 days (October 2002 to March 2003), suggesting that some resting positions were more suitable than others.

\section{Site Fidelity}

The 40 identified $O$. ornatus were observed on 133 occasions over the 100-day observation period. Five individuals were not resighted after their first identification, and 10 individuals were resighted only once after their first identification (Figure 6). The greatest resighting frequency was 11 . The frequency distribution of resightings did not follow a Poisson distribution $(G=37.39$, $\mathrm{df}=10, P<0.001)$ : the frequency of 0 and 


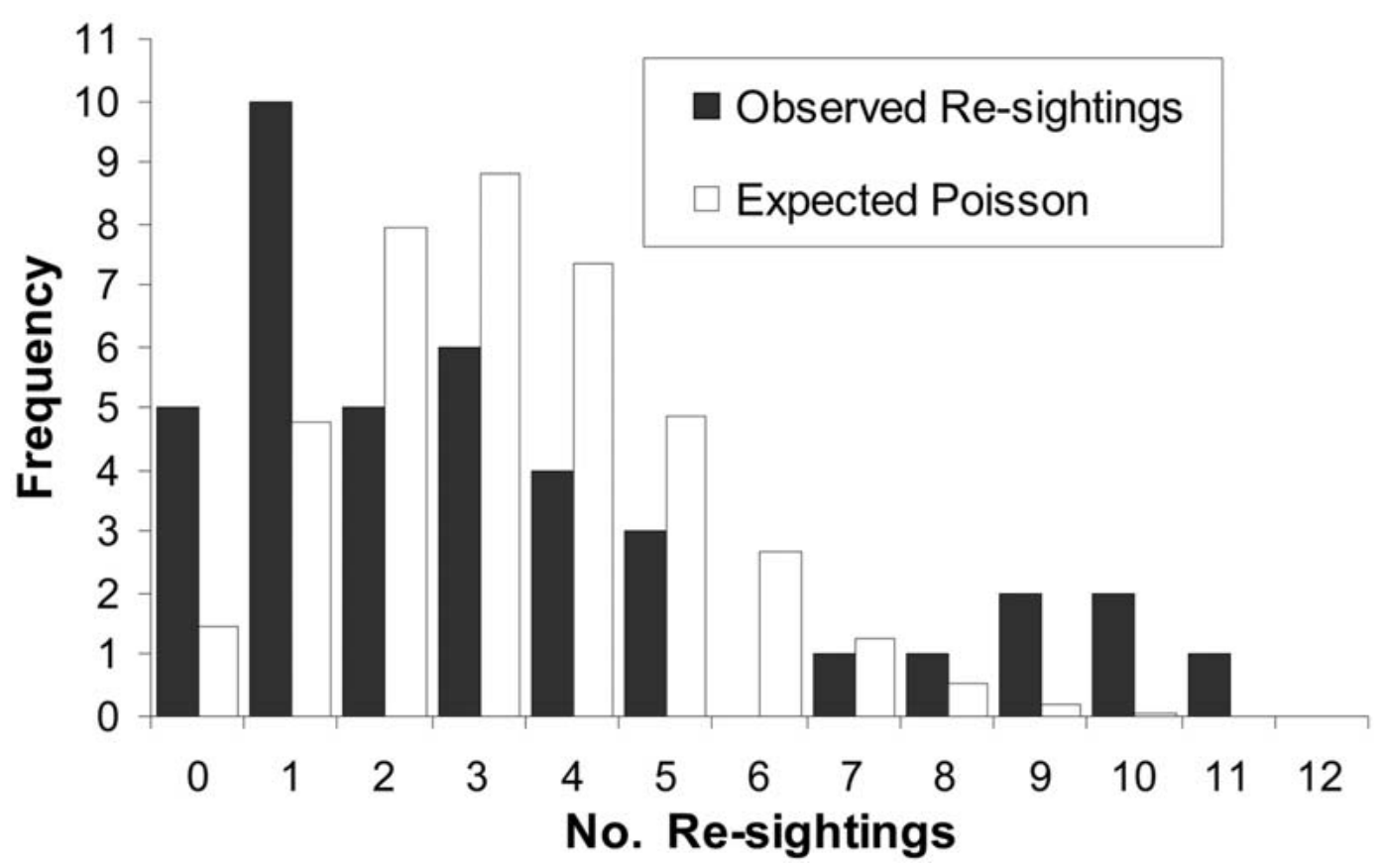

FIGURE 6. Frequency distribution of resightings of individually identified Orectolobus ornatus over a 100-day period and a Poisson distribution assuming resightings are randomly distributed.

7-11 resightings was greater than expected and the frequency of $2-5$ resightings was less than expected. The frequency distribution of resightings (Figure 6) suggests that individuals fell into two groups: those that were resighted frequently (7-11 resightings) and those resighted infrequently $(0-5$ resightings). The latter group included an individual resighted after an absence of 88 days and 13 individuals (eight males and five females of $0.8-1.3 \mathrm{~m} \mathrm{TL}$ ) with resighting intervals of $>20$ days. Despite regular, biweekly surveys of the study area only two of the identified individuals were resighted after the 100-day period: a tagged $1.25-\mathrm{m}$ male was resighted on single occasions 117 days and 172 days after tagging, and a tagged $1.05-\mathrm{m}$ male was resighted 211 days after tagging. On all occasions these individuals occupied a resting position within $10 \mathrm{~m}$ of the position where they were tagged.

Tagged individuals were resighted more frequently $(5.7 \pm 1.4$ resightings) than photographed $(3.1 \pm 0.7)$ or drawn $(2.6 \pm 0.6)$ in- dividuals, but the difference between the three identification methods was not significant (Kruskal-Wallis test, $\chi^{2}=3.63, \mathrm{df}=2$, $P>0.05)$. There was no significant difference between the resighting frequencies of males and females (Kruskal-Wallis test, $\chi^{2}=$ $0.001, \mathrm{df}=1, P>0.05)$ or of sharks $<1 \mathrm{~m}$ TL and $\geq 1 \mathrm{~m}$ TL (Kruskal-Wallis test, $\chi^{2}=$ $0.002, \mathrm{df}=1, P>0.05)$.

Individuals displayed fidelity to specific resting positions. One individual at Little Beach was observed in the same position on 10 surveys of the 12 surveys conducted there over 100 days. Another individual was observed in the same resting position at Halifax Park on 10 consecutive surveys over 59 days. An individual that was absent from the reserve for 95 days returned to the same resting position at Fly Point it had occupied before its departure. Of resighted sharks $76.8 \%$ were observed within $20 \mathrm{~m}$ of their previous sighting. Two sharks moved between areas: a 0.98-m female moved from Little Beach to Halifax Park (a distance of $300 \mathrm{~m}$ ); and a 


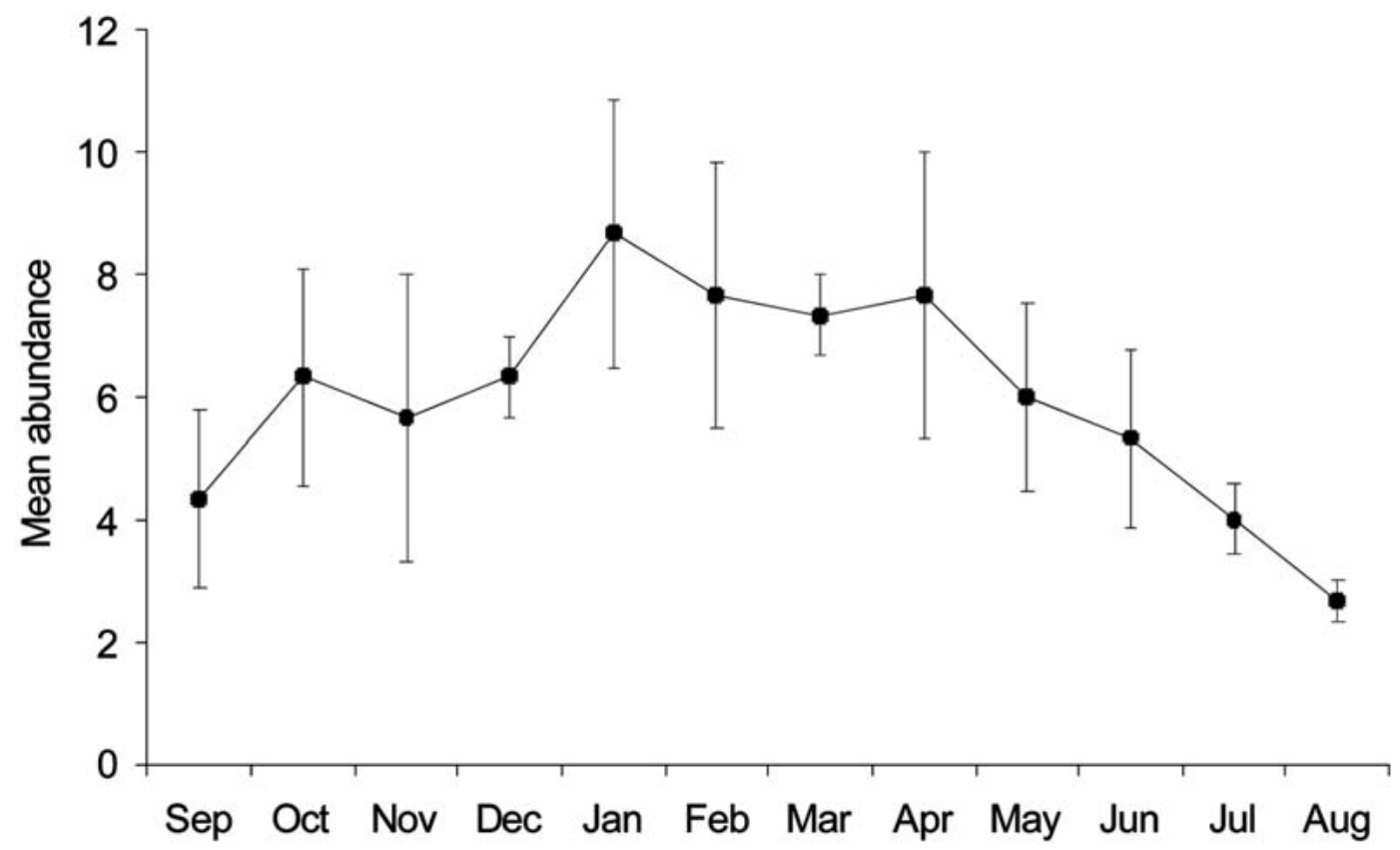

FIgURE 7. Mean ( \pm SE) abundance of Orectolobus ornatus in the study area. Mean values are based on the three study sites.

1.05-m male moved from Fly Point to Halifax Park (a distance of $>1,000 \mathrm{~m}$ ), where it was seen on a further nine occasions within a $\sim 20$-m radius.

\section{Abundance, Sex Ratio, and Length}

Abundance of $O$. ornatus increased between September 2002 and January 2003, remained relatively stable until April 2003, and then declined until the last survey in August 2003 (Figure 7). Average shark abundance in January 2003 was double the abundance in September 2002 and three times that in August 2003. At the time of peak abundance 13 sharks were recorded in the transect at Halifax Park, seven in the transect at Fly Point, and six in the transect at Little Beach. At the last survey in August 2003 there were two sharks at Halifax Park, three at Fly Point, and three at Little Beach. Overall, the abundance of $O$. ornatus varied significantly through time (Huynh-Feldt epsilon $=0.99$; $F=2.61 ; \mathrm{df}=11,22 ; P<0.05)$.

Sex ratio varied through time (Pearson $\left.\chi^{2}=19.08, \mathrm{df}=11, P=0.05\right)$. There were more males than females in the transects on most survey occasions, with the exception of April and May 2003 when numbers of females exceeded the numbers of males (Figure 8). The sex of a number of sharks in each survey could not be determined because of an obstructed view; however, their numbers were low relative to the numbers of confirmed males and females.

The TL of O. ornatus observed during the monthly surveys ranged from 0.5 to $1.3 \mathrm{~m}$ (mean $\pm \mathrm{SE}=0.98 \pm 0.01 \mathrm{~m}, n=215$ ). Three smaller sharks $(0.35,0.23$, and $0.40 \mathrm{~m})$ were observed on other occasions. Mean TL varied significantly between monthly surveys $(F=3.46 ; \mathrm{df}=11,203 ; P<0.001 ;$ Levene's statistic $=0.70, P=0.65$ ) (Figure 9). Mean TL decreased from $1.1 \pm 0.04 \mathrm{~m}$ in November to $0.9 \pm 0.04 \mathrm{~m}$ in January and then gradually increased over the remainder of the study period. The smaller TL in December 2002 and January 2003 was due to an increased abundance of smaller females and a reduced abundance of larger males. 


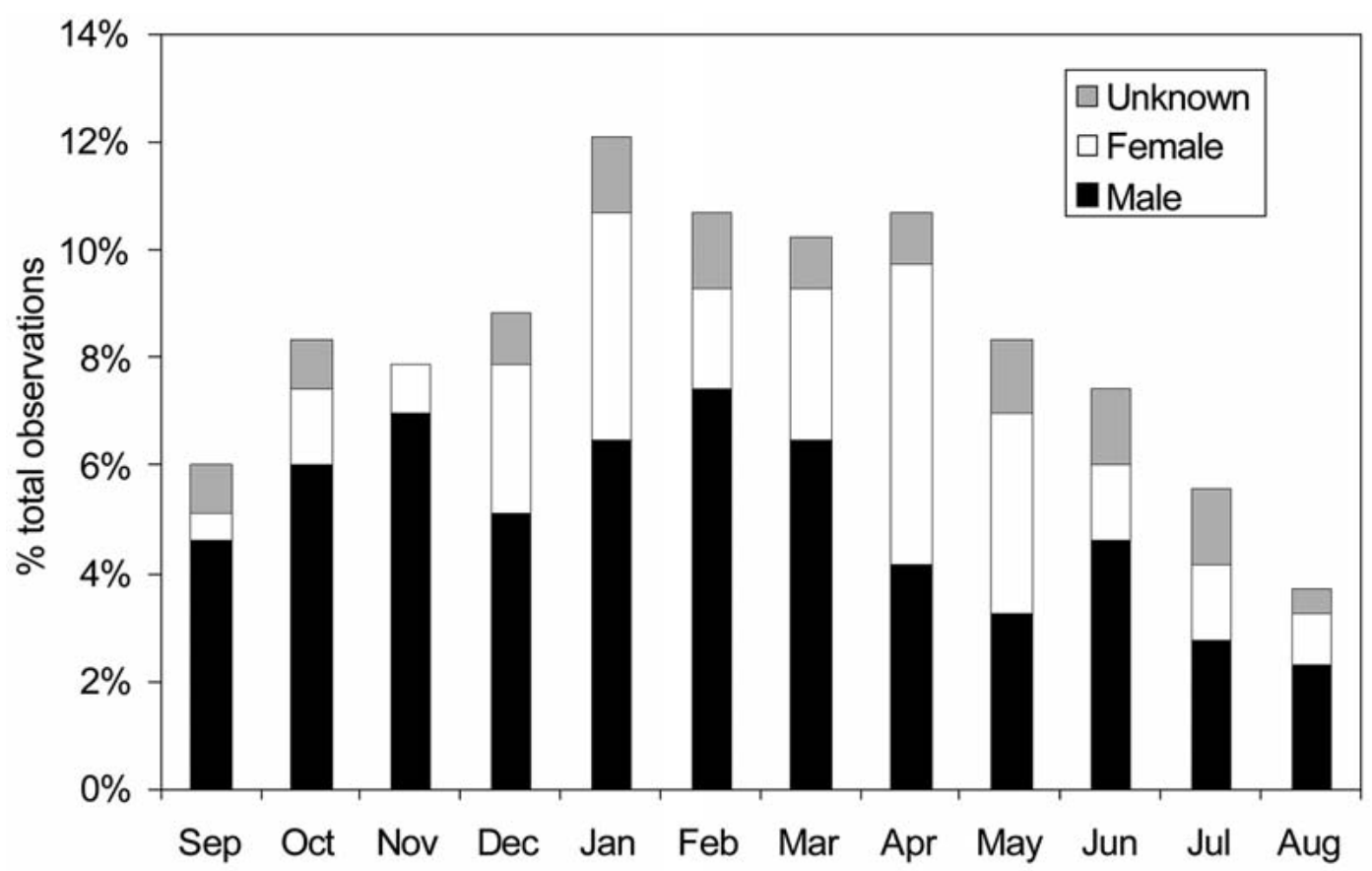

Figure 8. Numbers of males, females, and individuals of unknown sex of Orectolobus ornatus observed between September 2002 and August 2003.

\section{DISCUSSION}

The preferred habitats of $O$. ornatus were sponge gardens, barren boulders, and artificial structures. Although these habitats differed in biogenic composition they overlapped in depth distribution and were the most topographically complex habitats. All habitat types occurred at the Little Beach site, but almost all O. ornatus there occupied artificial structures. This probably occurred because the sponge gardens and barren boulders occurred on gently sloping shelves and, unlike the other sites in the study area, provided no shelter or protection. Artificial structures are used by fishes for shelter and foraging (Hair and Bell 1992, Carr and Hixon 1997), but their importance for elasmobranchs is less well known. Multivariate analysis of the biophysical attributes of resting positions found that the most consistent features distinguishing resting positions from a random selection of positions were high topographic complexity and greater crevice volume. It therefore appears that $O$. ornatus preferred sponge gardens, barren boulders, and artificial structures because of the structural complexity they provided.

The depth preferences of $O$. ornatus at Halifax Park correspond with areas of greater structural complexity. The 4- to 12-m range includes the steep slope and large boulders of grid reference D1 and the $12-\mathrm{m}$ ridge (D6); the 16- to 20-m contour contains the twin bommies (patch reefs) (F4 and F5) and other smaller features (Figure 5). These depth ranges contain a number of crevices of potential resting positions and were strongly utilized by O. ornatus. By comparison the depth ranges avoided or not selected consist of shallow water $(0-4 \mathrm{~m})$, broad sponge plateaus $(12-16 \mathrm{~m})$, and flat areas of sand with few structural elements.

Orectolobus ornatus may have selected structurally complex habitats and resting positions to avoid predators. Predators such as the tiger shark (Galeocerdo cuvier), bull shark (Carcharbinus leucas), and the great white shark (Car- 


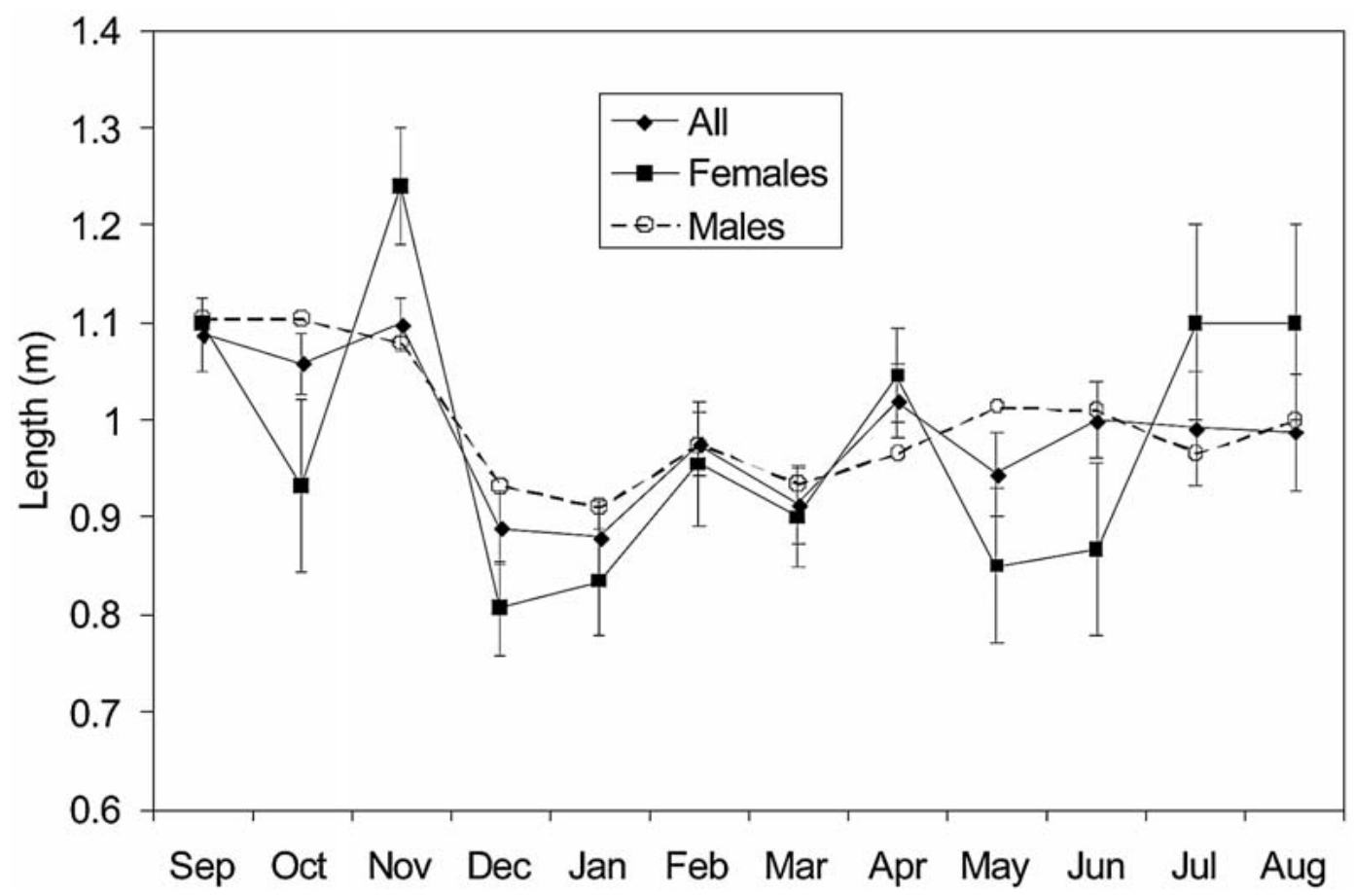

FIGURE 9. Mean total length ( \pm SE) of Orectolobus ornatus in the study area between September 2002 and August 2003.

charodon carcharius) are occasionally seen within Port Stephens, and large numbers of sharks were fished from the area in the early twentieth century (Roughley 1955), suggesting that predation by larger sharks may be a risk for O. ornatus in the study area. All O. ornatus observed were in the size range 50 to $140 \mathrm{~cm}$ TL (including two pregnant females of $120 \mathrm{~cm}$ and $140 \mathrm{~cm} \mathrm{TL}$ ), and there was no difference in the habitat preferences of individuals $<1 \mathrm{~m}$ and $>1 \mathrm{~m}$. This indicates that predation risk is similar across the size range observed in the study. Reduction of predation risk has been hypothesized to be responsible for habitat preferences in the nursery grounds of lemon sharks, Negaprion brevirostris (Morrisey and Gruber 1993a); blacktip sharks, Carcharbinus limbatus (Heupel and Heuter 2002); and sandbar sharks, Carcharbinus plumbeus (Rechisky and Wetherbee 2003). Demonstration of the value of preferred habitats for predator avoidance requires experimental evaluation, predator surveys, or observations of higher predation rates in other habitats. An alternative explanation for the observed habitat and microhabitat preferences of $O$. ornatus is that existence of strong tidal currents (three to four times daily) within the study area may encourage the use of crevices for shelter. However, O. ornatus has also been observed offshore residing in crevices where no current was present (pers. obs.).

The absence of a relationship between the small-scale distribution and abundance of $O$. ornatus and fish abundance is surprising, given that O. ornatus is piscivorous (Last and Stevens 1994). However, predatory attacks upon fishes from a position within a topographically complex shelter site may be physically difficult. Limited nocturnal observations in the study area of predation by O. ornatus on fishes showed that this occurred away from shelter and as ambush predation. Many shark species feed infrequently and follow this with long periods of inactivity (Heithaus 2004). Nocturnal feeding, the use of an ambush 
feeding strategy, and infrequent feeding would decouple the relationship with diurnal fish abundance. Quantitative studies of predator distribution and abundance and prey density in elasmobranches are uncommon (Heithaus 2004), and such studies have shown that prey availability was influential in the habitat preferences of tiger sharks (Heithaus et al. 2002) but was not correlated with the habitat preferences of blacktip sharks (Heupel and Heuter 2002).

This study used direct observations by divers to determine the daytime habitat and microhabitat preferences of $O$. ornatus. This was feasible because underwater visibility is $7-15 \mathrm{~m}$ throughout the year, large sections of the study area are able to be searched by divers in a single day (thus avoiding temporal confounding of observations of individual sharks), and all of the study area is accessible from the shore. Acoustic telemetry may have been impractical for daytime monitoring of $O$. ornatus because of its habit of sheltering in physically complex habitats that would have impeded acoustic signals. Acoustic telemetry at night will provide information on nocturnal habitat preferences when $O$. ornatus is foraging in the open; however, of the $37 \mathrm{O}$. ornatus observed at night 14 were in the same shelter sites occupied during the day. Further research is required to study movement patterns at a larger scale and to identify home ranges or migratory patterns within and beyond Port Stephens.

None of the individually identified $O$. ornatus was a permanent resident of the study area over the time scale of the intensive surveys (100 days). Some individuals exhibited short-term temporary fidelity to the study area, being resighted frequently for part of the intensive surveys. Other individuals were temporary visitors, being resighted only on $0-1$ occasions after initial identification or returning after extended absences. Only two male individuals were resighted in the study area within 6 months of the end of the intensive surveys, indicating that some temporary visitors use the reserve regularly but only for short periods of time. Subsequent sightings of the same two males occurred 12 and 24 months after completion of the study. Both were sighted within $5-15 \mathrm{~m}$ of their previous resting locations. The resighting of some individuals following an absence suggests that the reefs in the reserve may be a part of a larger home range. The possibility that individual sharks did not leave the reserve but remained hidden and undetected during the intensive surveys is unlikely. The monthly population surveys confirmed significant changes over time in the abundance, sex ratio, and length of $O$. ornatus in the study area, indicating a change in composition of the population. The study area was surveyed frequently using an intensive searching technique for tagged and recognizable individuals. The reserve is also very popular with recreational divers and at the start of the tagging period an awareness program was mounted with local dive shops and at the entry points to the dive sites advising divers about the presence of tagged sharks in the reserve and requesting information about sightings. The sightings of tagged sharks reported by divers coincided with our observations at the same time.

Changes in abundance, length, and sex ratio and the relative lack of movement between sites within the study area suggest that the population of $O$. ornatus that utilized the study area was dynamic and reflected movements by individuals at a much larger spatial scale. Individual $O$. ornatus were temporary residents of the study area, and some individuals returned for short periods of time after long absences. Although advocated for a range of conservation and management issues (Halpern and Warner 2002, Gladstone et al. 2003), marine reserves will only be effective for species' conservation when they are located and designed in accordance with life history requirements and habitat preferences. Reserves suitable for O. ornatus conservation will need to include their preferred habitats (barren boulders, sponge, artificial structures) with a high structural complexity. However, the lack of long-term site fidelity suggests that reserves may not be effective when used as the sole management strategy. Further research is needed to determine the nature of O. ornatus site fidelity at much larger spatial scales. 


\section{ACKNOWLEDGMENTS}

The design of this study benefited from initial discussions with N. Otway and D. Harasti. D. Pollard, M. Lincoln Smith, D. Harasti, D. Powter, J. Morton, and N. Otway and two anonymous reviewers provided helpful comments on early versions of the manuscript. Thanks to G. Lewis and N. McCarthy for assistance with diving and fieldwork and the divers of Nelson Bay for providing information. Tagging was done under permits P01/0064 from NSW Fisheries and ACEC 8100803 from the University of Newcastle's Animal Care and Ethics Committee.

\section{Literature Cited}

Bell, S. S., E. D. McCoy, and H. R. Mushinsky. 1991. Habitat structure: The physical arrangement of objects in space. Chapman and Hall, London.

Carr, M. H., and M. A. Hixon. 1997. Artificial reefs: The importance of comparisons with natural reefs. Fisheries (Bethesda) 22:28-33.

Cavanagh, R. D., P. M. Kyne, S. L. Fowler, J. A. Musick, and M. B. Bennett. 2003. The conservation status of Australian chondrichthyans. Report of the IUCN Shark Specialist Group Australia and Oceania Regional Red List workshop, University of Queensland, Brisbane.

Choat, J. H., and D. R. Bellwood. 1985. Interactions amongst herbivorous fishes on a coral reef: Influence of spatial variation. Mar. Biol. (Berl.) 89:221-234.

Clarke, K. R., and R. M. Warwick. 2001. Change in marine communities: An approach to statistical analysis and interpretation, 2nd ed. PRIMER-E, Plymouth.

Gladstone, W., F. Krupp, and M. Younis. 2003. Development and management of a network of marine protected areas in the Red Sea and Gulf of Aden region. Ocean Coast. Manage. 46:741-761.

Goldman, K. J., and S. D. Anderson. 1999. Space utilization and swimming depth of white sharks, Carcharodon carcharias, at the South Farallon Islands, central California. Environ. Biol. Fishes 56:351-364.
Hair, C. A., and J. D. Bell. 1992. Effects of enhancing pontoons on abundance of fish: Initial experiments in estuaries. Bull. Mar. Sci. 51:30-36.

Halpern, B. S., and R. R. Warner. 2002. Marine reserves have rapid and long lasting effects. Ecol. Lett. 5:361-366.

Heithaus, M. R. 2004. Predator-prey interactions. Pages 487-521 in J. C. Carrier, J. A. Musick, and M. R. Heithaus, eds. Biology of sharks and their relatives. CRC Press, Boca Raton.

Heithaus, M. R., L. M. Dill, G. J. Marshall, and B. Buhleier. 2002. Habitat use and behavior of tiger sharks (Galeocerdo cuvier) in a seagrass ecosystem. Mar. Biol. (Berl.) 140:237-249.

Heupel, M. R., and M. B. Bennett. 1997. Histology of dart insertion sites in the epaulette shark. J. Fish Biol. 50:1034-1041.

Heupel, M. R., and R. E. Hueter. 2002. The importance of prey density in relation to the movement patterns of juvenile sharks within a coastal nursery area. Mar. Freshwater Res. 53:543-550.

Holland, K. M., B. M. Wetherbee, J. D. Peterson, and C. G. Lowe. 1993. Movements and distribution of hammerhead shark pups on their natal grounds. Copeia 1993:495-502.

Jones, G. P., and C. Syms. 1998. Disturbance, habitat structure and the ecology of fishes on coral reefs. Aust. J. Ecol. 23:287-297.

Kohler, N. E., and P. A. Turner. 2001. Shark tagging: A review of conventional methods and studies. Environ. Biol. Fishes 60:191223.

Kramer, D. L., and M. R. Chapman. 1999. Implications of fish home range size and relocation for marine reserve function. Environ. Biol. Fishes 55:67-79.

Last, P. R., and J. D. Stevens. 1994. Sharks and rays of Australia, CSIRO, Australia.

Legendre, P., and L. Legendre. 1998. Numerical ecology, 2nd ed. Elsevier Science, Amsterdam.

Manly, B. F. 1997. Randomization, bootstrap, and monte carlo methods in biology, 2nd ed. Chapman and Hall, London.

Manly, B. F., L. L. MacDonald, and D. L. Thomas. 1993. Resource selection by ani- 
mals: Statistical design and analysis for field studies. Chapman and Hall, London.

McCormick, M. I. 1994. Comparison of field methods for measuring surface topography and their associations with a tropical reef fish assemblage. Mar. Ecol. Prog. Ser. 112:87-96.

McKibben, J. N., and D. R. Nelson. 1986. Patterns of movement and grouping of grey reef sharks, Carcharbinus amblyrbynchos, at Enewetak, Marshall Islands. Bull. Mar. Sci. 38:89-110.

Morrissey, J. F., and S. H. Gruber. $1993 a$. Habitat selection by juvenile lemon sharks, Negaprion brevirostris. Environ. Biol. Fishes 38:311-319.

. 1993b. Home range of juvenile lemon sharks. Copeia 1993:425-434.

NSW Fisheries. 2002a. Discussion paper: Management of wobbegong sharks in NSW. NSW Fisheries, Sydney. 2002b. Grey nurse shark (Carcharias taurus) draft recovery plan. NSW Fisheries, Sydney.

Otway, N. M., and P. C. Parker. 2000. The biology, ecology, distribution and abundance, and identification of marine protected areas for the conservation of the threatened grey nurse sharks in South East Australian waters. NSW Fisheries Final Report Series No. 19. NSW Fisheries, Sydney.

Pielou, E. C. 1977. Mathematical ecology. John Wiley and Sons, New York.

Pogonoski, J. J., D. A. Pollard, and J. R. Paxton. 2002. Conservation overview and action plan for Australian threatened and potentially threatened marine and estuarine fishes. Environment Australia, Canberra.
Quinn, G. P., and M. J. Keough. 2002. Experimental design and data analysis for biologists. Cambridge University Press, Cambridge.

Ray, G. C., and J. McCormick-Ray. 2004. Coastal-marine conservation: Science and policy, Blackwell, Malden.

Rechisky, E. L., and B. M. Wetherbee. 2003. Short-term movements of juvenile and neonate sandbar sharks, Carcharbinus plumbeus, on their nursery grounds in Delaware Bay. Environ. Biol. Fishes 68:113128.

Roughley, T. C. 1955. Fish and fisheries of Australia. Angus and Robertson, Sydney.

Samoilys, M. 1997. Movement in a large predatory fish: Coral trout, Plectropomus leopardus (Pisces: Serranidae), on Heron reef, Australia. Coral Reefs 16:151-158.

Simpfendorfer, C., and M. R. Heupel. 2004. Assessing habitat use and movement. Pages 553-572 in J. C. Carrier, J. A. Musick, and M. R. Heithaus, eds. Biology of sharks and their relatives. CRC Press, Boca Raton.

Sokal, R. R., and F. J. Rohlf. 1995. Biometry, 3rd ed. W. H. Freeman, New York.

Syms, C. 1995. Multi-scale analysis of habitat association in a guild of blennioid fishes. Mar. Ecol. Prog. Ser. 125:31-43.

Tabachnick, B., and L. Fidell. 1989. Using multivariate statistics. Harper and Row, New York.

Underwood, A. J., M. J. Kingsford, and N. C. Andrew. 1991. Patterns in shallow subtidal marine assemblages along the coast of New South Wales. Aust. J. Ecol. 6:231249. 
